\title{
El cuerpo en tiempos de pandemia. Una mirada foucaultiana a los decretos, los protocolos y las publicidades contra el covid-19
}

The body in times of pandemic. A Foucauldian look at the decrees, protocols and advertisements against covid-19

\author{
Nicolás Patierno \\ CONICET - Facultad de Humanidades y Ciencias de la \\ Educación. Universidad Nacional de La Plata, Argentina \\ nicolaspatierno@gmail.com \\ iD https://orcid.org/0000-0002-3411-7309
}

\begin{abstract}
RESUMEN:
El objetivo de este artículo es analizar las representaciones del cuerpo que subyacen a los decretos, los protocolos y las publicidades dirigidas a promover y sostener el Aislamiento Social Preventivo y Obligatorio dispuesto en la ciudad de La Plata durante gran parte del año 2020 como medida preventiva para frenar los contagios de covid-19. Desde el cierre de ingresos hasta las instrucciones para el lavado de manos, la organización de la vida en esta coyuntura epidemiológica parece organizarse en función del riesgo biológico que representa nuestro cuerpo, concebido como un conjunto de micropartículas potencialmente "cargadas" con un virus sumamente contagioso. Siguiendo a Foucault en Vigilar y castigar, el temor a los contagios es una constante que, desde los tiempos de la peste negra, se ha materializado en disposiciones gubernamentales que, si bien han variado a lo largo del tiempo en función de los avances en medicina, tecnología y comunicaciones, mantienen una preocupación constante: la clasificación y la normalización de los cuerpos. Desde un punto de vista ético, cabe señalar que este artículo no incursionará en asuntos médicos referidos al tratamiento del covid-19, ni cuestionará la efectividad de las medidas preventivas implementadas para combatir la pandemia en Argentina.
\end{abstract}

Palabras Clave: Cuerpo, Pandemia, Covid-19, Aislamiento, Normalidad.

\section{Abstract:}

The objective of this article is to analyze the representations of the body that underlie the decrees, protocols and advertisements aimed at promoting and sustaining the Preventive and Mandatory Social Isolation provided in the city of La Plata during much of 2020 as a preventive measure to stop the spread of COVID-19. From the ceasing of income to the instructions for hand washing, the organization of life in this epidemiological scenario seems to be ordered according to the biological risk that our body represents, conceived as a set of microparticles potentially "loaded" with a highly contagious virus. Following Foucault in Discipline and Punish, the fear of contagion is a constant that, since the times of the Black Death, has been materialized in government regulations that, although they have varied over time depending on advances in medicine, technology and communications, maintain a constant concern: the classification and normalization of bodies. From an ethical point of view, it should be noted that this article will not delve into medical matters related to the treatment of COVID-19, nor will it question the effectiveness of the preventive measures implemented to fight the pandemic in Argentina.

KeYwords: Body, Pandemic, COVID-19, Isolation, Normality.

\section{INTRODUCCIÓN}

Considerando que gran parte de la información disponible sobre el coronavirus puede provenir de fuentes poco científicas o puede estar sesgada por intereses políticos, considero apropiado iniciar este artículo con algunas aclaraciones éticas. Tomé la decisión de elaborar este escrito en el marco del número temático "Educación en Pandemia y Postpandemia", propuesto por la revista Educación Física y Ciencia y desde el rol de docente-investigador dedicado al estudio del cuerpo y temáticas afines. Por lo tanto, si bien 
se analizarán algunos documentos elaborados con fines sanitarios -como decretos, protocolos, campañas publicitarias e informes publicados por organismos científicos-, las páginas que siguen no ahondan en cuestiones específicamente epidemiológicas. Dicho de otro modo, el presente artículo constituye un registro más -subjetivo y parcial- de un problema global del que se hablará por muchos años y sobre el que, muy probablemente, volvamos una y otra vez para repensar posiciones y certezas.

El artículo está contextualizado en Argentina, más específicamente en la ciudad de La Plata (Provincia de Buenos Aires), durante el primer Aislamiento Social Preventivo y Obligatorio (ASPO). El criterio para seleccionar este recorte se centra en el hecho que, al momento de finalizar este escrito (junio del año 2021), nos encontramos transitando lo que los medios apodan "la segunda ola"; una especie de rebrote del covid-19 con nuevas variantes y con un número de contagios considerablemente mayor a "la primera ola". La vertiginosidad y mutabilidad de este virus nos obliga a asumir que, a pesar de las medidas preventivas, los tratamientos experimentales, los fármacos y las esperanzadoras campañas de vacunación, la pandemia aún no concluyó. Además, en sintonía con las aclaraciones éticas antes mencionadas, no podemos perder de vista que los estudios sobre este virus aún son muy recientes como para tratar de predecir su circulación en el futuro.

Siguiendo con los aspectos constitutivos del artículo, el marco de referencia empírico se centra en las medidas sanitarias implementadas en la ciudad de La Plata y alrededores. Pero antes de adentrarnos específicamente en esta cuestión, repasemos brevemente algunas de las acciones preventivas efectuadas por el gobierno nacional para "mitigar el impacto sanitario del covid-19":

Durante la vigencia del “aislamiento social, preventivo y obligatorio", las personas deberán permanecer en sus residencias
habituales o en la residencia en que se encuentren a las 00:00 horas del día 20 de marzo de 2020 , momento de inicio de la
medida dispuesta. Deberán abstenerse de concurrir a sus lugares de trabajo y no podrán desplazarse por rutas, vías y espacios
públicos. [...] El MINISTERIO DE SEGURIDAD dispondrá controles permanentes en rutas, vías y espacios públicos,
accesos y demás lugares estratégicos que determine, en coordinación y en forma concurrente con sus pares de las jurisdicciones
provinciales (Poder Ejecutivo Nacional, Decreto de Necesidad y Urgencia 297/2020). ${ }^{1}$

Replicando los aislamientos implementados en la mayoría de los países occidentales a mediados de marzo del año 2020, Argentina inició oficialmente el suyo el día 20 de marzo. El covid-19 no llegó en un buen momento económico para el país. El gobierno del Frente de Todos, inaugurado sólo tres meses antes de la llegada de la pandemia, debió enfrentar el doble desafío de contener la propagación de un virus extremadamente contagioso en el marco de una profunda crisis económica (marcada por el endeudamiento público, el ajuste en salud, trabajo y educación, y el aumento de la inflación, el desempleo y la pobreza); entre otras consecuencias de la gestión de Juntos por el Cambio. Por otra parte, dos de los rasgos ideológicos más significativos del partido gobernante son la defensa de los derechos humanos y el repudio al uso institucional de la violencia, por lo tanto, la gestión de la pandemia obligó al flamante gobierno a enfrentarse con una serie de disyuntivas que, en otro contexto, hubieran sido impensadas. Dicho de otro modo, la cuestión a resolver era -y en cierto modo sigue siendo- ¿cómo llevar adelante un mandato eficiente en términos sanitarios preservando los derechos humanos y evitando, en la medida de lo posible, emplear la fuerza pública?

A medida que fue avanzando el otoño del 2020, el coronavirus gradualmente se fue propagando por la región de La Plata y, junto con esta circunstancia biológica, los platenses nos fuimos adaptando al confinamiento domiciliario, a las restricciones en la circulación, el distanciamiento entre personas y la limitación de actividades sociales. En resumen, los espacios comunes y, por ende, propicios para "la circulación y el contagio del virus covid-19" (Poder Ejecutivo Nacional, ibid.), estuvieron afectados por una serie de medidas sanitarias, jurídicas -y también morales-, establecidas específicamente para asegurar la separación y el contacto entre los cuerpos. Ahora bien, es preciso aclarar que, en esta ciudad -y en la mayoría de los centros urbanos de Argentina-, en lugar de la vigilancia directa aplicada por la fuerza, en términos generales se apeló a la responsabilidad individual. En pocas palabras, no se cerraron las puertas desde afuera. Esto significa que, si bien el aislamiento pudo haber generado cierto descontento general, y, por añadidura, algunos cuestionamientos vinculados a la aplicación de algunas medidas disciplinares, en 
retrospectiva, sería desatinado hablar de la radicalización de alguna de estas dimensiones o de la instauración de un nuevo régimen de control. De acuerdo con Ferrán, Singer y Vignale, "los encierros o las cuarentenas son herramientas posibles en el contexto de la administración poblacional, pero ya no son la ratio principal desde la cual se opera y la finalidad tampoco es la normalización o la producción de cuerpos dóciles" (2020, p. 55).

Pese a esta aclaración, también es preciso señalar que, en muchos barrios vulnerables y periféricos de la ciudad de La Plata, a diferencia del centro, se establecieron puestos de vigilancia policial y seguimiento médico con la finalidad de llevar a cabo un control riguroso sobre poblaciones que, debido a la precariedad y el hacinamiento, representaban una potencial fuente de propagación del virus. Anticipando uno de los debates centrales del artículo, esta súbita presencia de organismos gubernamentales en barrios humildes funcionó como una respuesta urgente, provisoria -y en ocasiones intempestiva- para mitigar el inminente aumento de contagios. De acuerdo al Relevamiento del impacto social de las medidas del Aislamiento (2020), en estos sectores, el resguardo en espacios seguros y habitables fue -y sigue siendo- materialmente imposible, ya que, como consecuencia de una deuda histórica, la falta de infraestructura y servicios dificultan considerablemente el cumplimiento de las recomendaciones sanitarias básicas.

\section{MARCo TEÓRICO}

El marco teórico elegido para el desarrollo del escrito se centra en los aportes de Michel Foucault plasmados en Vigilar y castigar, obra publicada hace casi cincuenta años en la que el pensador francés analiza la evolución del sistema penitenciario del siglo XVIII al siglo XIX, haciendo énfasis en las relaciones de poder, las técnicas de vigilancia y la aplicación de las penas. A pesar del tiempo transcurrido y aunque pueda sonar anacrónico, los pasajes dedicados al exilio del leproso y la vigilancia de los apestados como antesala del panoptismo, tienen más coherencia y fundamentos que las fake news y las opiniones de los nuevos "expertos mediáticos" en coronavirus; dos fuentes de desinformación -peligrosamente influyentes- sobre la, ya instalada, confusión social generalizada. Cabe señalar que, aunque suene tentador, este artículo no se enfoca únicamente en la búsqueda de continuidades entre las cuarentenas europeas del siglo XVIII y el ASPO argentino del 2020; ni tampoco se propone analizar la obra citada en términos predictivos. Siendo coherentes con el pensamiento del autor, la obra será leída tratando de identificar aquellos conceptos claves que, sobre todo en la segunda parte del artículo, enriquecen las reflexiones sobre nuestro presente. ${ }^{2}$

La vigencia de Vigilar y castigar no sólo marca la continuidad del pensamiento de Foucault, también nos invita a reconsiderar el hecho de que, con ciertos recaudos teóricos, muchos de los problemas vinculados al control de esta pandemia, no son tan nuevos como creemos. Cabe señalar que el marco teórico también se compone de fuentes secundarias, más precisamente, recupera algunas publicaciones recientes de Edgardo Castro y de Paul Preciado, entre otros investigadores dedicados a analizar la coyuntura epidemiológica actual desde una perspectiva foucaultiana.

\section{¡CiUdad aislada!}

En el comienzo del capítulo titulado El panoptismo, Foucault analiza algunos reglamentos de finales del siglo XVIII dirigidos al control de la peste en las grandes ciudades europeas. ${ }^{3}$ En una estricta y minuciosa segmentación que va desde la división geográfica de la ciudad hasta el cuerpo individual de sus habitantes, para el filósofo, el control gubernamental de la peste "constituye un modelo compacto del dispositivo disciplinario" (2002, p. 202). Para frenar el avance de esa enfermedad infecciosa, los primeros gobiernos modernos ensayaron lo que Foucault describe como una "física" o una "anatomía" del poder; una serie de medidas dirigidas a la aplicación y el perfeccionamiento de lo que, analíticamente, podríamos categorizar como una "mecánica del poder". 
La ciudad apestada, toda ella atravesada de jerarquía, de vigilancia, de inspección, de escritura, la ciudad inmovilizada en el funcionamiento de un poder extensivo que se ejerce de manera distinta sobre todos los cuerpos individuales, es la utopía de la ciudad perfectamente gobernada (Foucault, 2002, p. 203).

Entre las medidas dispuestas para el control de la peste, se destacan: el cierre de la ciudad, la división de esta en secciones administradas por un intendente; la inspección constante de un síndico; el aislamiento de los ciudadanos "so pena de vida" (el cual debía realizarse "desde fuera" por una autoridad, quien, a su vez, también sería castigado con pena de muerte si abandonara su puesto). El aprovisionamiento, debía realizarse a través de un sistema de sogas y poleas que asegurase el distanciamiento entre el proveedor y las familias. En cuanto a la circulación, esta era permitida únicamente cuando fuere necesaria, debiendo realizarse por turnos y evitando todo encuentro con otras personas. En las calles solo podían circular los intendentes, los síndicos, los soldados de la guardia, y, entre las casas infectadas, los "cuervos" (quienes trasportaban a los enfermos, enterraban a los muertos, limpiaban y hacían muchos oficios "viles y abyectos"). En resumen, el control de la peste fue llevado a cabo con argumentos sanitarios, legales y morales, dispuestos minuciosamente para gobernar -de manera simultánea- aspectos generales (como el espacio público) y aspectos individuales (como las actividades y las relaciones personales). En términos del propio Foucault: "a la peste responde el orden [...], prescribe a cada cual su lugar, a cada cual su cuerpo, a cada cual su enfermedad y su muerte" (ibid.).

A fin de entender mejor la evolución en el control de las enfermedades infecciosas en la Europa del siglo XVIII y las consecuencias políticas que, desde el siglo XIX, se extenderían por Occidente, Foucault marca algunas diferencias entre la administración disciplinar de la peste y la gestión excluyente de la lepra. Para el manejo de la lepra, históricamente se implementaron mecanismos de expulsión y encierro, es decir, la identificación del leproso implicaba, automáticamente, la suspensión de sus libertades y su traslado hacia instituciones ubicadas en las afueras de la ciudad, en otras palabras, lejos de la mirada evaluadora de los "ciudadanos de bien". Aunque estos leprosarios o leprocomios fueron dispuestos para el tratamiento de los leprosos, el filósofo francés advierte que, en realidad -y, considerando que el cristianismo históricamente asoció esta enfermedad con la lujuria y la promiscuidad-, su población también estaba compuesta por mendigos, vagabundos, locos, homosexuales y violentos, en suma, por todo aquél que no encajara con los estándares poblacionales "normales". De acuerdo con Castro: "el modelo lepra representa un modelo de exclusión; el modelo peste, en cambio, es un modelo de la distribución de los individuos en un espacio cuadriculado y de la formación de un sistema de recolección de datos” (2004, p. 396). Cabe resaltar que, debido al rechazo, el temor y las representaciones negativas que solían envolver la lepra y la peste, quienes eran señalados como infectados, rápidamente se convertían en la personificación de todos los males. En palabras de Foucault: "detrás de los dispositivos disciplinarios, se lee la obsesión de los 'contagios', de la peste, de las revueltas, de los crímenes, de la vagancia, de las deserciones, de los individuos que aparecen y desaparecen, viven y mueren en el desorden" (2002, p. 202).

A medida que fue avanzando el siglo XIX, las técnicas implementadas para el control de la lepra y la peste se fueron entremezclando en función de un poder disciplinario cada vez más incisivo y excluyente. Siguiendo a Ferrán, Singer y Vignale: "el primero es propiamente represivo: aísla y excluye. El segundo es disciplinario, encierra solamente con la finalidad de ordenar, analizar, cuadricular, inspeccionar y enderezar, se articula así una anátomo-política” (2020, p. 55). Poco a poco, el espacio de la exclusión -cuyo habitante representativo era el leproso- fue administrado con técnicas específicamente disciplinarias como la segmentación del espacio, la supresión de derechos, la regulación de actividades, etcétera. Resumidamente, estas técnicas perseguían dos objetivos: el primero consistía en la "división binaria", esto es, una diferenciación justificada mediante la aplicación de un parámetro legítimo. De esta manera, personas "autorizadas" como funcionarios, jueces y médicos, podían -y pueden- determinar quién está enfermo y quién está sano; quién está loco y quién está cuerdo o quién es peligroso y quién es inofensivo. En suma, la división binaria establece la diferenciación entre lo normal y lo anormal. El segundo de los objetivos era la "distribución diferencial", es decir, la asignación coercitiva de un espacio, un rol, y, por añadidura, un tratamiento específico. Esta técnica 
sirve para esclarecer quién es quién, dónde debe estar, por qué caracterizarlo, cómo reconocerlo y cómo ejercer sobre él, de manera individual, una vigilancia constante.

Recapitulando, las experiencias acumuladas durante la gestión de la peste en Europa, lejos de acotarse a un hecho anecdótico, abonaron la configuración -simbólica y material- de las instituciones panópticas, esto es, un mecanismo disciplinar diseñado para vigilar -incisiva e individualmente-a los sujetos institucionalizados. Para Foucault, el miedo a la peste incentivó todo un conjunto de técnicas y de instituciones que se atribuyen como tarea mucho más que tratar los síntomas de la enfermedad. El temor al contagio habilitó nuevos mecanismos para "medir, controlar y corregir a los anormales" (2002, p. 204).

\section{Un vistazo a la gestión de la PANDEmia de Covid-19 en Argentina}

En un período de pocas semanas entre febrero y marzo de 2020, la gran mayoría de los países occidentales tomaron una serie medidas restrictivas en las que resonaron palabras que no se oían globalmente desde los tiempos de la peste o de la -comúnmente denominada- gripe española: confinamiento, aislamiento, clausura, cuarentena, prevención, resguardo, cierre, reclusión, distanciamiento... Súbitamente debimos adaptarnos a una cotidianeidad que muchas generaciones sólo conocimos a través de los libros. En este marco, presumiendo que una de las principales fuentes de propagación del covid-19 fueron los viajeros, una de las medidas replicadas por todos los países del mundo para frenar esta amenaza, fue el cierre total de sus fronteras. Algo parecido ocurrió con nuestros cuerpos. De manera repentina y global se establecieron una serie de medidas que nos obligaron a modificar acciones tan mundanas como toser, tocarse los ojos o acercarse a otras personas. Anticipando el análisis, podría decirse que el aislamiento afectó -simultánea, obligatoria y apresuradamente- tanto las fronteras de los países como las fronteras del cuerpo. Para entender mejor el alcance y la celeridad de estas medidas sanitarias, me parece oportuno narrar un testimonio personal.

Si bien resido en la ciudad de La Plata, Provincia de Buenos Aires (Argentina), la emergencia sanitaria mundial desatada por la pandemia de covid-19 me encontró realizando una estadía en la Universidad Federal de Santa Catarina, Florianópolis (Brasil). El 17 de marzo de 2020, luego de la cancelación de mi vuelo de regreso a la Argentina, el cierre de fronteras entre Argentina y Brasil y la ausencia de información en el aeropuerto y el consulado, súbitamente experimenté, por unos pocos días, la situación de "varado". Una circunstancia excepcional marcada por la incertidumbre y por una relativa vulnerabilidad (dependiendo de los recursos económicos y de la cobertura médica de cada viajero).

Después de varias gestiones con la aerolínea, el 22 de marzo pude regresar a la Argentina en uno de los vuelos popularmente denominados "de repatriación". Al poco tiempo de que el avión se estabilizó en el aire y las azafatas desinfectaran la cabina de pasajeros, comenzó un protocolo de evaluación epidemiológica, el cual constaba de varios registros. El primer paso fue completar, durante el vuelo, una declaración jurada de síntomas compatibles con el covid-19. Una vez aterrizado el avión, el mismo fue inspeccionado por personal sanitario -cubiertos de pies a cabeza- con un termómetro que medía la temperatura de todos los pasajeros, quienes, por orden de las azafatas, no podíamos movernos de nuestros asientos.

$\mathrm{Al}$ momento del arribo, cerca de la medianoche, el aeropuerto de Ezeiza revelaba una inusual presencia de funcionarios, médicos, científicos y militares. El camino desde el avión hasta la oficina de migraciones constantemente custodiado por oficiales aeroportuarios ubicados a los laterales del recorrido-, fue revelando imágenes que, siendo exagerados, parecían extraídas de un film de ficción. Las cámaras térmicas, los puestos de testeos y el personal sanitario conformaban una postal que crisparía al mismo Foucault.

Llegando al final del recorrido, unos policías aeroportuarios nos ordenaron en una fila asegurándose que mantengamos una distancia mínima de dos metros entre los recién arribados. Por último, en el puesto de migraciones, además del habitual control de documentación, debíamos completar una nueva declaración jurada, ya que, como medida preventiva adicional, debíamos declarar "bajo pena de arresto", el sitio donde 
realizaríamos los catorce días de cuarentena dispuesta para quienes retornábamos del exterior; una especie de "reclusión total" dentro del ya vigente ASPO.

Pasada la medianoche llegué a La Plata, una ciudad que, a simple vista, se hallaba completamente paralizada. Una circunstancia excepcional, considerando que al tratarse de la capital de la Provincia de Buenos Aires, esta urbe se caracteriza por un movimiento constante de vehículos y de transporte público. Estaba claro que el movimiento se había interrumpido, y, en una atmósfera sumamente enrarecida, La Plata había cambiado drásticamente desde la última vez que la vi, solo unos pocos meses atrás. A dos días de haberse decretado el aislamiento, la imagen nocturna, con calles vacías y silenciosas, se asemejaba mucho a una verdadera "ciudad fantasma". Siendo imaginativos, podríamos decir que, a pesar de los años, las ciudades "aisladas" de hoy se asemejan -temerosamente- a la Vincennes "apestada" de Foucault, descrita por él como un "espacio recortado, inmóvil, petrificado. Cada cual está pegado a su puesto. Y si se mueve, [...] contagio o castigo" (2002, p. 200).

Puertas adentro la situación no era muy esperanzadora. La información disponible en los medios y las redes divulgaban postales dantescas en las que se entremezclaban, allá lejos, en Asia y Europa, imágenes inéditas de contagios, internaciones y muertes; acá cerca, en los supermercados, gente comprando grandes volúmenes de papel higiénico. Mientras tanto, en los principales programas de debate periodístico, las discusiones se centraban -con un enfoque moralizante, $y$, al mismo tiempo, sensacionalista- en asuntos exclusivamente sanitarios como la escasez de insumos médicos, la capacidad hospitalaria, la efectividad de las mascarillas, las técnicas de testeo, el alcance de las partículas del estornudo y los síntomas más comunes de la enfermedad. Como si esto fuera poco, el principal canal de comunicación elegido por el gobierno fue la transmisión oficial en vivo de conferencias encabezadas por los principales referentes del poder ejecutivo, y, en la misma sala, una novedad inquietante: un equipo de médicos y científicos especializados en infectología, biología molecular, virología, inmunología, etcétera. Para entender mejor el tratamiento mediático del confinamiento y el clima social vivido durante el comienzo del ASPO, considero pertinente citar a Scharagrodsky, quien relata muy bien las preocupaciones más recurrentes de esos días:

La escala transnacional del fenómeno, los efectos en la organización social, política y económica mundial, la recurrencia y la forma en que los medios de comunicación están enunciando -y produciendo- la pandemia, los prolongados confinamientos de millones de personas, la implementación como nunca antes de políticas masivas estatales de ayuda laboral, económica, social, alimentaria, etc. y la cada vez mayor interdependencia entre los países afectados, son algunos de los aspectos que ubican al virus en una dimensión socio-política -y diplomática- inusitada y, al mismo tiempo, configuran un escenario con consecuencias inciertas y desconocidas (2020, p. 2).

\section{"Quedate EN CASA"}

Entre las acciones preventivas que se replicaron en la ciudad de La Plata -sobre todo en el casco urbano y al comienzo de lo que posteriormente conoceríamos como la "fase uno"-, hubo tres que, por características que ya analizamos, podrían acercarse al modelo disciplinar. Entre las medidas citadas, en primer lugar debemos mencionar el patrullaje vehicular de la policía regional pregonando mensajes en sus altavoces para que los vecinos permanezcan sus casas. Cabe señalar que este patrullaje en ocasiones estuvo reforzado con el vuelo de helicópteros de la Policía de la Provincia de Buenos Aires. En segundo orden, se dispuso un número telefónico para que los ciudadanos puedan denunciar a quienes transgredan el aislamiento. Y, por último, se colocaron carteles, afiches y videos en la vía pública con diversos lemas instando a las personas a regresar a sus casas. En sintonía con Foucault (2002), podríamos decir que, considerando la finalidad y la amplitud de estas medidas, allí convergen varias técnicas de vigilancia. Algunas apelan a la inspección directa y punitiva (como el rastrillaje de la fuerza pública) y otras, en cambio, más sutiles, recurren a la culpa y el remordimiento a través de mensajes cargados con un fuerte contenido moral (como los afiches publicados en espacios comunes). Siendo ensayistas, la combinación de estas técnicas sugiere que las respuestas gubernamentales actuales al avance 
de la pandemia de coronavirus revelan la permanencia relativa de algunos elementos propios del esquema disciplinario.

Centrando la mirada en la campaña publicitaria, más específicamente, en los afiches, a diferencia de los vistosos carteles publicitarios, estos fueron diseñados con letras blancas y fondo negro, muy probablemente con la intención de transmitir un mensaje claro y conciso dirigido a las personas que estuviesen violando el aislamiento. De esta manera, las paradas de micros, los postes de luz, la cartelería pública y hasta los letreros digitales instalados en las avenidas comerciales fueron utilizados para publicar frases como: "nos ponés en riesgo a todos"; "la mentira tiene patas cortas y consecuencias largas"; "¿estás dispuesto a contagiar a tu familia?”; “¿realmente preferís lamentarte a cuidarte?”; “¿quién te hizo creer que sos inmune?” En la parte inferior de estos, el mensaje se reforzaba con el lema de la campaña publicitaria: "volvé a tu casa” y, más abajo, se podía ver el logo del municipio acompañado por el hashtag "quedate en casa". Dado que las frases condensan las representaciones más resonantes de la primera parte del ASPO, considero que, en términos analíticos, este material contiene información crucial para entender el contexto y, sobre todo, los temores más recurrentes del primer aislamiento.

Cabe señalar que estos afiches también poseen una fuerte carga moral dirigida a lo que Foucault categorizaría como una "práctica de sí", es decir, el contenido de los mensajes intentaba despertar cierta responsabilidad en el lector, ya que, recordemos, los afiches fueron distribuidos mientras regía el momento más restrictivo del ASPO. Profundizando este análisis, detengámonos un momento en la moral foucaultiana y repasemos de qué manera la entiende el filósofo francés:

Por "moral" entendemos el comportamiento real de los individuos, en su relación con las reglas y valores que se les proponen: designamos así la forma en que se someten más o menos completamente a un principio de conducta, en que obedecen una prohibición o prescripción o se resisten a ella, en que respetan o dejan de lado un conjunto de valores (2016, p. 26).

Si bien es preciso aclarar que esta definición fue extraída de Historia de la sexualidad 2 y está enfocada al estudio de la sexualidad y los placeres, es de mucha utilidad para analizar los prejuicios y las valoraciones negativas que históricamente marcaron las representaciones del cuerpo, en este caso, particularmente asociadas al acercamiento, el roce, y la mescolanza. En este marco interpretativo, el distanciamiento social explicitado en el Decreto 297/2020, podría considerarse como una respuesta biopolítica al "riesgo biológico" que implica exponerse a las micropartículas - potencialmente infectadas- resultantes de la exhalación. Siguiendo estas recomendaciones, el acercamiento representa una violación de las medidas preventivas y, como en la Vincennes del siglo XVIII, tal exposición al contagio también conlleva una condena social ligada a la transgresión, el descontrol, la vagancia, la fiesta, y la promiscuidad. Al respecto, en Vigilar y castigar, Foucault expresa: "contra la peste que es mezcla, la disciplina hace valer su poder que es análisis. Ha habido en torno de la peste toda una ficción literaria de la fiesta: las leyes suspendidas, [...] los cuerpos mezclándose sin respeto, los individuos que se desenmascaran" (2002, p. 182).

\section{LA CLASIFICACIÓN DE LOS CUERPOS}

Rastreando continuidades entre el control de la peste desarrollado por Foucault y la gestión de la pandemia actual de covid-19, a primera vista podemos identificar el temor al contagio como una constante que, antes y ahora, fue respondida por la mayoría de los gobiernos con el establecimiento de una emergencia sanitaria. En uno y otro tiempo, dicho estado de excepción incluyó una serie de restricciones tendientes a, como dijimos, mantener una separación determinada entre los cuerpos. Como vimos a lo largo del año 2020, esta medida generó cambios sustanciales en la vida cotidiana de la gran mayoría de ciudadanos. Desde entonces -y hasta el día hoy- los saludos, las comunicaciones, los acercamientos, los traslados, los trabajos, y, sobre todo, las actividades sociales, cambiaron sustancialmente. Siguiendo a Žižek: 
Podemos esperar que las epidemias virales afecten nuestras interacciones más elementales con otras personas y objetos que nos rodean, incluidos nuestros propios cuerpos; evite tocar cosas que puedan estar (invisiblemente) sucias, no toque los picaportes, no se siente en asientos de inodoros o bancos públicos, evite abrazar a las personas o estrechar sus manos. Incluso podríamos ser más cuidadosos con los gestos espontáneos: no te toques la nariz ni te frotes los ojos (2020, p. 28).

Ahora bien, dejando de lado el debate por la eficacia y la implementación de estas medidas -ya que no es objetivo de este artículo refutar investigaciones tendientes a combatir la enfermedad-, no podemos pasar por alto el hecho de que todas las regulaciones tendientes a mitigar la pandemia de covid-19, están dirigidas a un minucioso y hasta microscópico control y registro de las relaciones entre los cuerpos. Parafraseando a Castro (2020), sabemos que esta nueva normalidad va a estar marcada por un registro médico, lo sanitario. A diferencia de lo que sucedió en la concepción liberal de la modernidad, donde el eje estaba puesto en la dimensión jurídica (los derechos, las libertades individuales), ahora vamos a tener un registro más marcado por la dimensión médica.

Si nos dejásemos llevar por las recomendaciones sanitarias y los protocolos contra el covid-19, el cuerpo parece reducirse a un conjunto de células, microorganismos y sistemas fisiológicos que, por sus cualidades orgánicas, son incumbencia de determinados campos disciplinares. En un contexto de pandemia, donde el temor y la paranoia influyen determinantemente en el clima social, la palabra de "los especialistas" en general es recepcionada como sinónimo de verdad; como argumento indiscutible y, en cierto modo, como un antídoto contra la incertidumbre. Durante el ASPO, las opiniones de los infectólogos sobre el avance de los contagios, el sistema hospitalario y la efectividad de las vacunas recorrieron todos los canales de comunicación. Aunque pueda sonar reiterativo, en este punto me parece necesario recalcar que no es objetivo de este artículo analizar el valor científico de estos discursos. A diferencia de los nuevos "conspiracionistas" y “oportunistas mediáticos", sólo me limitaré al análisis del valor de verdad que envuelve su discurso y, por supuesto, a su influencia sobre las representaciones del cuerpo. ${ }^{4}$ Haciendo énfasis en esta cuestión, es decir, en el efecto que el discurso médico-científico actualmente tiene sobre los modos en que concebimos nuestro cuerpo, podríamos decir que, con una celeridad excepcional -ya que estamos hablando de un período de menos de dos años- las regulaciones para frenar la pandemia fueron conformando un modelo de cuerpo que, siguiendo a Preciado, podríamos categorizar como un "cuerpo post pandemia/ideal". Siguiendo esta línea, el cuerpo que circula en espacios colectivos "no tiene piel, es intocable, no tiene manos. No intercambia bienes físicos, paga con tarjeta de crédito. No tiene labios, no tiene lengua. [...] No se reúne ni se colectiviza. Es radicalmente individuo. No tiene rostro, tiene máscara (Preciado, 2020, p. 178).

Siendo esquemáticos, podría decirse que el Estado se adentra en el cuerpo a través de un proceso de biocontrol que, si bien comienza desde afuera -a través de regulaciones científicamente avaladas-, rápidamente va decantando en forma de "adaptaciones sanitarias" sobre acciones tan mundanas como saludarse, dialogar, estornudar, tocarse la nariz o la boca. ${ }^{5}$ Tanto a nivel "macro" como a nivel "micro", la vida en la pandemia va moldeando un cuerpo marcado por un evento epidemiológico omnipresente. Siguiendo con Preciado:

Las distintas epidemias materializan en el ámbito del cuerpo individual las obsesiones que dominan la gestión política de la vida y de la muerte de las poblaciones en un periodo determinado. Por decirlo con términos de Foucault, una epidemia radicaliza y desplaza las técnicas biopolíticas que se aplican al territorio nacional hasta al nivel de la anatomía política, inscribiéndolas en el cuerpo individual (2020, p. 167).

En este marco, el espacio público, o, mejor dicho -el espacio amenazante y confuso que constituye el afuera- es el lugar dónde las restricciones y las representaciones sobre el cuerpo adquieren más relevancia, no sólo por el control directo de la fuerza pública, sino también por las imágenes publicitarias, los protocolos, las miradas evaluadoras y los murmullos. En el exterior, el cuerpo representa una amenaza biológica. Cada individuo, con su cuerpo cargado de un arsenal de micropartículas sólo puede moverse dentro de un rango de dos metros de diámetro. Respetar esa distancia es sinónimo respetar la comunidad. Esa coreografía sanitaria, 
popularizada con el lema "juntos pero separados”, representa muy bien la dicotomía resultante de considerar al otro respetando una distancia "biológicamente segura". Ampliando el debate, uno de los grandes desafíos que la experiencia del ASPO nos deja para el futuro es la búsqueda de medidas anti-pandemia efectivas en materia sanitaria que, a su vez, posibiliten la vida en sociedad. Resumiendo esta cuestión en algunos interrogantes, cabe preguntarnos ¿cómo aplicar medidas estatales tendientes a mitigar los contagios de una enfermedad altamente infecciosa asegurando la validez de todos los derechos colectivos? ¿Cómo organizar la población en el marco de una pandemia desalentando reacciones individualistas y desconsideradas? ¿Qué alternativas a las sanciones disciplinarias podrían implementarse para controlar el cumplimiento de las medidas sanitarias extraordinarias?

\section{Pandemia, aislamiento y Desigualdad}

Como en la peste del siglo XVIII, las medidas preventivas contra el covid-19 no están legitimadas únicamente desde un punto de vista sanitario, en las restricciones también convergen argumentos jurídicos y morales. Con algunas libertades interpretativas, podríamos decir que, los "desordenados" de Vincennes, hoy están representados en las grandes ciudades latinoamericanas por los pobres, los migrantes y los desplazados. Personas ya afectadas por una situación socio-económica adversa que, además, deben resistir una pandemia con muchísimas dificultades. Considerando el Relevamiento del impacto social de las medidas del Aislamiento (2020), Argentina enfrenta el reto de controlar una pandemia en un contexto de disparidades sociales y de carencias estructurales de larga data. Las dificultades para cumplir con las medidas de aislamiento y los problemas derivados de esta coyuntura, reflejan gravísimas carencias estructurales sufridas por vastos sectores y regiones del país. Tales insuficiencias remiten, en términos generales, a la elevada marginalidad, la precariedad ocupacional y a déficits de hábitat y vivienda.

Centrando la atención en la región del gran La Plata, de acuerdo al informe citado en el párrafo anterior, los sectores más humildes recibieron un tratamiento diferenciado por parte de las autoridades gubernamentales, ya que, debido al hacinamiento y la falta de medios para asegurar la higiene, registraron los primeros brotes locales del covid-19 (entre mayo y junio del año 2020). Esta situación pudo registrarse mayormente en barrios carenciados como el José Luis Cabezas, el Barrio Nuevo de Ringuelet, Arana, Los Hornos, Melchor Romero y San Carlos, entre otros. De acuerdo a los testimonios de los referentes barriales considerados en el informe mencionado, los residentes de estas zonas manifestaron serias dificultades para acatar las medidas vinculadas al aislamiento. Entre las problemáticas más recurrentes, se destacan:

a) El problema del ingreso monetario para el sostenimiento familiar, ya que se trata de una población cuya circulación fuera del barrio se encuentra caracterizada por el acceso al trabajo informal, changas, cartoneo o pedidos de comida en locales.

b) Las condiciones de viviendas precarias y el hacinamiento dificultan cumplir con el aislamiento en la vivienda.

c) La medida se entiende como "quedarse en el barrio", ya que "quedarse en casa" todo el día resulta impracticable debido a la falta de espacio, de elementos de juego, carencia de internet y/o televisión.

d) Resistencia por parte de los jóvenes a dejar de reunirse en sus espacios habituales de socialización (Kessler, 2020, p. 28).

Mientras que en el casco urbano eventualmente se implementaron técnicas disciplinarias que, en rigor, rara vez fueron aplicadas con el uso de la fuerza pública, en algunos barrios periféricos, la historia fue muy diferente. Incluso cuando el Segundo reporte de los casos de covid-19 en La Plata según delegaciones municipales, revelara que, en septiembre de 2020 el casco urbano registró la mayor concentración de casos confirmados (hasta esa fecha), el control de la pandemia en los sectores más alejados del centro fue realizado con dispositivos de vigilancia más directos e incisivos. Uno de los casos más resonantes en la región fue el 
aislamiento parcial del barrio José Luis Cabezas, una zona administrada por los municipios colindantes de Berisso y Ensenada, que, a su vez, limita con el Partido de La Plata por una avenida que recorre el límite este de la ciudad. Esto significa que, previo a la pandemia, los residentes del barrio en cuestión solían circular libremente por calles pertenecientes a los tres partidos.

Una vez que se registraron los primeros casos de covid-19, la Policía de la Provincia de Buenos Aires, junto con las secretarías de salud de los municipios de Berisso y Ensenada, montaron una especie de bloqueo en la entrada del barrio (con patrulleros, carpas y puestos de testeo), impidiendo, durante los primeros 23 días del mes de junio de 2020, la circulación de los vecinos. Una de las cuestiones más relevantes de este caso es que, pese a la difusa y compleja extensión del barrio, una vez confirmados los primeros contagios, la zona fue minuciosamente censada y parcialmente "cerrada desde afuera", con un notorio despliegue de recursos gubernamentales y una cobertura mediática inusitada. Desde un punto de vista asistencial, podríamos decir que el blindaje sirvió para ayudar a las personas infectadas a sobrellevar su enfermedad, y, además, también sirvió para a frenar el aumento de los contagios. Por otra parte, siendo anacrónicos, controversiales $-\mathrm{y}$ coherentes con el marco teórico del artículo-, también podemos inferir que el rigor del blindaje en zonas de alto riesgo epidemiológico en verdad fue llevado a cabo para que, en términos foucaultianos, el virus no llegue a los hogares "de bien", situados dentro de los límites "estéticos" las ciudades.

Para entender mejor los detalles del caso, a continuación citaré algunos fragmentos de informes periodísticos publicados por agencias de noticias nacionales, provinciales y municipales (referidos específicamente al barrio José Luis Cabezas y a otros barrios de las mismas características).

Los intendentes de Berisso y Ensenada, en conjunto con las autoridades provinciales, decidieron aislar un sector que alcanza al 12\% del territorio del barrio "José Luis Cabezas" donde se detectaron, un total de 39 casos positivos de COVID-19. [...] Según se informó se trata aproximadamente de 220 personas ubicadas en una especie de apéndice paralelo a las vías (calle 56) que alcanzaría alrededor de dos cuadras. Cabe mencionar que 54 casos se encuentran en estudio" (Archivo de noticias - Municipalidad de Berisso, 2020).

Desde ambos municipios llevan adelante desinfecciones además del control de la fiebre de las vecinas y los vecinos casa por casa y la realización de los hisopados a personas con síntomas. Se cuenta con la presencia permanente de la Policía Ecológica para higienizar a cada uno de las vecinas y los vecinos que ingresan o egresan en la parte del barrio que no se encuentra aislado (Noticias de Mujeres, Políticas de Género y Diversidad Sexual - Gobierno de la Provincia de Buenos Aires, 2020).

[En barrios populares de La Plata] realizaron controles sanitarios casa por casa, verificaron la temperatura corporal y realizaron testeos olfativos a 747 personas, con el fin de detectar posibles síntomas asociados con el Covid-19. En Arana, tres camiones hidrantes recorrieron las calles rociando con diversas soluciones desinfectantes las superficies de calles, veredas y frentes de comercios esenciales (Télam S.E. Agencia Nacional de Noticias, 2020).

La reclusión forzada de las personas más pobres en sus propios barrios nos enfrenta cara a cara con una paradoja dolorosa e inocultable: las instituciones que habitualmente estuvieron ausentes en estos territorios, irrumpieron súbita -y en ocasiones violentamente-, con argumentos sanitarios, jurídicos y morales para llevar a cabo un control de la pandemia mucho más riguroso -y estigmatizante- que en otros sectores de la ciudad. Si bien es preciso ahondar más en registros locales como para establecer categorías de análisis apodícticas, los datos disponibles en informes publicados por universidades y organismos científicos, nos permiten vislumbrar que en la región del gran La Plata, el control de la pandemia recrudeció los procesos de clasificación y discriminación históricamente arraigados en nuestra región.

El trazado de la ciudad de La Plata, claramente delimitado por una avenida que recorre toda la circunferencia del casco urbano original, sirvió de frontera para diferenciar entre unos mecanismos de vigilancia "céntricos y persuasivos" - tendientes a la concientización- y otros "periféricos y coercitivos" tendientes a la inspección directa y, eventualmente, a la intervención. De esta manera, la condición de "pobre", "indigente", "vulnerable", entre otros, sirvió de argumento para la identificación, el examen y la aplicación de una serie de medidas sanitarias que, debido a la precariedad de su hábitat, no podían -ni pueden- cumplir por sí mismos. Dicho de otro modo, la gestión del covid-19 reveló una problemática compartida con otras grandes ciudades latinoamericanas: cómo exigir el cumplimiento de una serie de 
disposiciones higiénicas en lugares dónde, incluso mucho antes de la llegada de la pandemia, la falta de recursos era -y sigue siendo-, un problema sumamente grave en términos de salud pública. En estos contextos, era ingenuo asumir que la repentina llegada del Estado y la policía iban a ser bienvenidas. Por el contrario, el descontento y los conflictos con las fuerzas de seguridad no tardaron en llegar. En este sentido, considero oportuno citar un fragmento del Relevamiento del impacto social de las medidas del Aislamiento, en el que se hace referencia a los conflictos con la policía:

En los barrios relevados, en no pocas situaciones la presencia policial genera conflictos (obstaculización de la llegada a centros de salud o servicios fuera del barrio, o a los comedores; y restricción de las posibilidades de realizar tareas que aseguran algún tipo de ingreso para las familias como cartonear) que podrían evitarse, si otros agentes públicos y sociales mantuvieran algún tipo de comunicación con los/as vecinos/as en los barrios (Barrios José Luis Cabezas y El Dique de Ensenada, Barrio Las Vías y La 90 en Villa Elvira en La Plata; Parque Pereyra Iraola en La Plata) (Kessler, 2020, p. 31).

Si bien las acciones descritas no parecen remitir a situaciones de abuso directo o contacto físico, en una concepción más ampliada de la violencia -que considere los procesos históricos de discriminación y exclusión-, es evidente que la versión local del ASPO implicó un tratamiento diferencial de acuerdo al origen social de los potenciales infectados. En pocas palabras, podríamos decir que la severidad de los controles fue variando en relación a las condiciones socio-económicas de los diversos barrios platenses. Así, las zonas más vulnerables, compuestas en gran porcentaje por sectores marginados, fueron vigiladas con estrategias disciplinares cercanas al modelo de la peste desarrollado por Foucault. Por otra parte, en los barrios más céntricos, el control de la circulación y el distanciamiento fue llevado a cabo a través de acciones indirectas y "más morales", como la publicidad y las aplicaciones en el teléfono celular.

\section{UN PRESENTE MARCADO POR LA BIOPOLÍTICA}

Pese a las diferencias socio-económicas y a la variabilidad en las técnicas de vigilancia, hay una constante que atraviesa todas las medidas preventivas: la biología del cuerpo humano. Desde el cierre de los aeropuertos hasta las instrucciones para el lavado de manos, cada una de las técnicas implementadas para tratar de frenar la pandemia de covid-19, parten del mismo supuesto: el cuerpo es un organismo biológico y esta condición es asunto de la medicina, un campo disciplinar que, en tiempos de pandemia, se consolida como el gran ordenador social. Parafraseando a Castro (2020), es claro que hay un peligro sanitario. La cuestión es si la vida, en términos políticos, puede ser achatada a la vida biológica; si lo que va a definir las libertades en un amplio sentido de posibilidades va a estar achatado sobre la necesaria seguridad médica de las poblaciones. Frente al temor que genera la posibilidad de contraer un virus sumamente contagioso y potencialmente mortal, el diagnóstico del especialista, hoy representado en la figura del "infectólogo", parece constituir el remedio contra el mal de esta época.

Ahora bien, Foucault nos ha advertido que, desde los albores de la modernidad, el valor de verdad que acompaña este saber médico-político, ha sido utilizado por los gobiernos como argumento central para ejercer y legitimar el control sobre la población de un territorio. Este mecanismo de gobierno, denominado por el filósofo como biopolítica, hace alusión a un vínculo explícito entre la política y la vida biológica, donde el Estado, lejos de ceñirse al discurso jurídico e impersonal del contrato social, actúa directamente sobre el cuerpo de los ciudadanos creando instituciones y aplicando prácticas de control biomédicas. En palabras del filósofo:

El control de la sociedad sobre los individuos no se operó simplemente a través de la conciencia o de la ideología, sino que se ejerció en el cuerpo, y con el cuerpo. Para la sociedad capitalista lo más importante era lo biopolítico, lo somático, lo corporal. El cuerpo es una realidad biopolítica; la medicina es una estrategia biopolítica (Foucault, 1999, p. 366).

En esta lógica, el hombre se vuelve objeto de la política por pertenecer a la especie humana, concebida, en estos términos, como un conjunto de seres vivientes agrupados bajo las mismas necesidades y gobernados 
en función de éstas. Volviendo sobre las palabras de Castro (2020), la biopolítica remite al gobierno de la vida biológica de la población. Los individuos estamos ligados por nexos biológicos y eso requiere, por parte del Estado, de técnicas de control y conceptos médicos. Lo mismo que caracteriza a lo humano, lo condena ineludiblemente a un tipo de gobierno particular, compuesto, en pocas palabras, por una serie de dispositivos tendientes al control de la natalidad, la reproducción y las enfermedades, entre otros dispositivos normalizadores que, por supuesto, cuentan con sus propios procedimientos. ${ }^{6}$ Analizando la pandemia de covid-19 con el prisma de la biopolítica foucaultiana, no podemos dejar de preguntarnos sobre los modelos en que se gestiona la salud de los ciudadanos y las técnicas de vigilancia implementadas. De acuerdo con Preciado, "dime cómo tu comunidad construye su soberanía política y te diré qué formas tomarán tus epidemias y cómo las afrontarás" (2020, p. 167).

\section{Conclusiones}

Llegando a esta instancia, me parece oportuno detenerme en una frase muy escuchada en estos tiempos: la "nueva normalidad"; una expresión recurrentemente utilizada en medios, redes y organismos internacionales para esquematizar cierto proceso de adaptación y naturalización de los cambios socio-políticos acontecidos durante la pandemia de covid-19. ${ }^{7}$ Si nos detenemos un momento a analizar la paradoja contenida en la frase, podemos entrever que, desde un enfoque más amplio, la "nueva normalidad" condensa algunos de los debates más resonantes del 2020: aislamiento/exposición; inmunidad/infección; prevención/ contagio; negligencia/enfermedad; restricción/propagación; presencialidad/virtualidad; apertura/cierre; aglomeración/distanciamiento; circulación/limitación, esencial/prescindible... Estos son sólo algunos de los problemas que marcaron la agenda socio-política de un año inolvidable.

Mientras que "lo nuevo", de acuerdo al Diccionario de la Real Academia Española, es definido como algo "distinto o diferente de lo que antes había o se tenía aprendido", la "normalidad" remite a algo "habitual", "ordinario" o "que se halla en su estado natural". Atendiendo a estas definiciones y los debates -arbitrariamente- anexados a la expresión en cuestión, podemos afirmar que la "nueva normalidad" es mucho más que una frase transitoria y sensacionalista. Este enunciado hace referencia a un proceso de adaptación y aceptación a una cotidianeidad marcada por una serie de protocolos y regulaciones dispuestos específicamente para clasificar y normalizar los cuerpos. Desde los controles en la circulación hasta las instrucciones para toser o estornudar, la organización de la vida en esta coyuntura epidemiológica parece organizarse en función del riesgo biológico que representa nuestro cuerpo, percibido como un conjunto de micropartículas potencialmente "cargadas" con un virus infeccioso. Ahora bien, como intenté exhibir a lo largo del artículo, Foucault nos ha enseñado que el gobierno de la peste negra en Europa no sólo sirvió para frenar los contagios de esa enfermedad; sino que la administración de ese acontecimiento epidemiológico cimentó un modelo político, o, mejor dicho, biopolítico, en el que la gestión de "lo corporal" o "lo somático" marcarían los modos de hacer política en las democracias occidentales modernas. Siendo ensayistas, si consideramos las teorías del filósofo francés al momento de analizar las medidas biopolíticas que se implementaron en nuestro lado del mapa a partir de la pandemia de covid-19, cabría preguntarnos ¿qué cambios socio-políticos sobrevendrán a la gestión del coronavirus? O, siendo más específicos ¿qué medidas sanitarias permanecerán con nosotros más allá del estado de emergencia implementado para frenar la propagación del covid-19?

En términos irónicamente "conspirativos", me animo a decir que esta pandemia no alteró el "orden mundial". Si tenemos en cuenta la sincronía casi total de los aislamientos, el cierre de fronteras internacionales y la similitud de las medidas sanitarias implementadas en el interior de la mayoría de los países occidentales, sería más atinado afirmar que, sobre todo en los meses más estrictos del aislamiento, las acciones tomadas para contener la "primera ola" del coronavirus representan, en pocas palabras, el triunfo de la biopolítica. A comienzos de marzo del año 2020, cuando Italia transitaba un aumento acelerado de contagios y una 
saturación del sistema hospitalario, Berardi afirmaba: "hemos entrado oficialmente en la era biopolítica, en la que los presidentes no pueden hacer nada, y solo los médicos pueden hacer algo" (2020, p. 52). Si bien estas palabras representan el pensamiento de muchos académicos en los tiempos más duros del primer brote, no podemos pasar por alto el hecho de que la preocupación global por el covid-19 ha revalorizado varios debates referidos al cuerpo y la biopolítica. De acuerdo con Ferrán, Singer y Vignale, "tal vez sea la primera pandemia que pone en juego y visibiliza enteramente aquel poder que comenzó a funcionar en el siglo XVIII" (2020, p. 51). Siguiendo esta línea de discusión, me parece oportuno añadir algunos interrogantes finales... ¿Qué papel jugará la medicina en los próximos trazados políticos? ¿En qué medida la contagiosidad del covid-19 seguirá marcando los modos de relacionarnos cara a cara? ¿De qué manera será habitado el espacio público a partir de esta coyuntura biológica? ¿Qué modelo de cuerpo prevalecerá en la "era post-covid"? ¿Qué cambios sociales y estructurales deberían afrontarse para evitar la propagación de enfermedades infecciosas en el futuro? Sin desestimar la experiencia acumulada durante los dos últimos años, considero que, dada la celeridad de los acontecimientos y la incertidumbre qué aún rodea todo lo referido al covid-19, sería apresurado responder estas cuestiones con cautela y rigor científico.

\section{ReFERENCIAS}

Argentina. Poder Ejecutivo Nacional. (2020). Decreto DNU 297 / 2020. Aislamiento Social Preventivo y Obligatorio. Recuperado de: https://www.argentina.gob.ar/normativa/nacional/decreto-297-2020-335741

Berardi, F. (2020). Crónica de la psicodeflación. En Sopa de Wuban. Pensamiento contemporáneo en tiempos de Pandemias. Capítulo 5. Recuperado de https://drive.google.com/file/d/1tShaH2j5A_9n9cWl6mhxtaHiGsJS Bo5k/view?fbclid=IwAR2yyZXK3w5riZKujJpkfIAicceOCQnHQKtlnQkuDzHW3aUja8CYenWI_lg

Castro, E. (2004). El vocabulario de Michel Foucault. Un recorrido alfabético por sus temas, conceptos y autores. Quilmes: Universidad Nacional de Quilmes.

Castro, E. (2020). El análisis que Michel Foucault dejó hace más de 30 años y cómo sirve para interpretar la 'nueva normalidad' en la era poscoronavirus [exclusivo en línea]. Keiser Report en Español. Recuperado de https://actu alidad.rt.com/actualidad/355225-filosofia-michel-foucault-normalidad-coronavirus

Diccionario de la Real Academia Española (2021). Versión en línea. Recuperado de www.rae.es

Ferrán, R., Singer, D. y Vignale, S. (2020). Usos de Foucault en pandemia. Lecturas sobre nuestra experiencia histórica de la peste. Bordes. Revista de politica, derecho y sociedad, 18, 51-62. En: http://revistabordes.unpaz.edu.ar/uso s-de-foucault-en-pandemia/

Foucault, M. (1999). Nacimiento de la medicina social. En: Estrategias depoder. Obras esenciales II. Barcelona: Paidós, 363-384.

Foucault, M. (2002). Vigilar y castigar: nacimiento de la prisión. Buenos Aires: Siglo XXI Editores Argentina.

Foucault, M. (2016). Historia de la sexualidad. 2 el uso de los placeres. Buenos Aires: Siglo XXI Editores.

Gobierno de la Provincia de Buenos Aires (4 de junio de 2020). Estela Díaz recorrió el Barrio José Luis Cabezas de Berisso y Ensenada. Noticias de Mujeres, Póliticas de Género y Diversidad Sexual. Recuperado de: https://www.gba.gob.ar/mujeres/noticias/estela_d\%C3\%ADaz_recorri\%C3\%B3_el_barrio_jos\%C3\%A9 _luis_cabezas_de_berisso_y_ensenada

Kessler, G. (coord.) (2020). Relevamiento del impacto social de las medidas del Aislamiento dispuestas por el PEN. Recuperado del Consejo Nacional de Investigaciones Científicas y Técnicas: https://www.conicet.gov.ar/wp-c ontent/uploads/Informe_Final_Covid-Cs.Sociales-1.pdf

Municipalidad de Berisso. (3 de junio de 2020). Aíslan un sector del barrio "José Luis Cabezas", donde se concentraron los casos positivos de COVID-19. Archivo de noticias. Recuperado de: http://berisso.gob.ar/noticia/aislan-un-s ector-del-barrio-jose-luis-cabezas-donde-se-concentraron-los-casos-positivos-de-covid-19

Patierno, N. (2017). Cuerpo y biopolítica: el totalitarismo como expresión radical de dominio. Intersticios, 11 (1), 129-136. https://www.intersticios.es/article/view/17307 
Preciado, P. (2020) Aprendiendo del virus. En Sopa de Wuhan. Pensamiento contemporáneo en tiempos de Pandemias. Cap. 17. Recuperado de: https://drive.google.com/file/d/1tShaH2j5A_9n9cWl6mhxtaHiGsJSBo5k/view?fbc lid=IwAR2yyZXK3w5riZKujJpkfIAicceOCQnHQKtlnQkuDzHW3aUja8CYenWI_lg

Scharagrodsky, P. (2020). Certezas, incertidumbres, posibilidades y desafíos. La pandemia de Covid-19 en la educación en Argentina. Olhar de professor, 24, 1-9. https://doi.org/10.5212/OlharProfr.v.24.15582.025

Télam S.E. Agencia Nacional de Noticias (4 de junio de 2020). Controlaron a casi 1.000 vecinos de barrios populares de La Plata. Política. Recuperado de: https://www.telam.com.ar/notas/202006/472422-controlaron-a-casi-10 00-vecinos-de-barrios-populares-de-la-plata.html

ŽiŽ̌ek, S. (2020). El coronavirus es un golpe al capitalismo a lo Kill Bill. En Sopa de Wuban. Pensamiento contemporáneo en tiempos de Pandemias. Cap.2. Recuperado de: https://drive.google.com/file/d/1tShaH2j5A_9n9cWl6mhxtaHiGsJSBo5k/view?fbclid=IwAR2yyZXK3 w5riZKujJpkfIAicceOCQnHQKtlnQkuDzHW3aUja8CYenWI_lg

\section{Notas}

1 A escala nacional, el ASPO estuvo vigente desde el 20 de marzo hasta el 26 de abril inclusive. A partir del 27 de abril, se establecieron medidas segmentadas territorialmente, de aislamiento o distanciamiento, de acuerdo a la situación epidemiológica de cada región. En el caso de la ciudad de La Plata, dado que se encuentra situada dentro del Área Metropolitana de Buenos Aires, esto es, una de las zonas en las que se registró -y se registra- más circulación de covid-19, las medidas sanitarias se prorrogaron -con una progresiva reducción de inspecciones-, hasta el 9 de noviembre del mismo año.

2 Aunque en Vigilar y castigar el filósofo francés aún no habla específicamente de biopolítica, Preciado señala que "entre 1975 y 1976, los años en los que publicó Vigilar y castigar y el primer volumen de la Historia de la sexualidad, Foucault utilizó la noción de "biopolítica” para hablar de una relación que el poder establecía con el cuerpo social en la modernidad" (2020, p. 164). Ferrán, Singer y Vignale (2020), por su parte, consideran que "los regímenes de saber y los dispositivos de poder no se siguen unos a otros como etapas evolutivas, sino que presentan superposiciones y supervivencias latentes" (2020, p. 51-52). En línea con los autores citados, adhiero a la posibilidad de leer la obra en cuestión articuladamente con la concepción de biopolítica. En este sentido, uno de los ejemplos más representativos es la afirmación -concisa y categórica- en la que Foucault sostiene que, desde el siglo XVIII, "los gobernantes soñaban con el estado de peste" (2002, p. 203).

3 Siendo más precisos, en una nota al pie, Foucault aclara que, si bien la información contenida en esa parte del capítulo fue extraída de un archivo militar de Vincennes (Francia), el reglamento es semejante a otros de la misma época o de un período anterior.

4 Entre los nuevos personajes que surgieron en esta pandemia, es pertinente incluir los “anticuarentenas” y los "antivacunas", un rejunte de incrédulos que -con argumentos incoherentes y sin contemplar ningún cuidado sanitario-, se manifiestan públicamente en contra del aislamiento y, en general, en contra de cualquier medida preventiva tendiente a mitigar los contagios.

5 Desde el comienzo de la pandemia, uno de los sitios web más popularizados en lo que refiere a protocolos sanitarios para prevenir el covid-19, fue -y sigue siendo- el de la Organización Mundial de la Salud (misma organización que, el 11 de marzo de 2020, caracterizó a la enfermedad por el covid-19 como una pandemia). Desde indicaciones en el uso de mascarillas y el abastecimiento de alimentos, hasta recomendaciones para toser y lavarse las manos, la OMS se ha convertido en una referencia a nivel mundial para determinar qué es recomendable y qué es desaconsejable hacer con nuestros cuerpos “para mantenerse y mantener a los demás a salvo de la covid-19”. Véase al respecto: https://www.wh o.int/es [consultado el 29 de junio de 2021].

6 Véase al respecto: Patierno (2017).

7 La UNESCO, por ejemplo, utilizó esta frase para titular una campaña audiovisual dirigida a repensar "el impacto de lo que consideramos normal para el medio ambiente, la economía, la salud pública y nuestras sociedades" (Organización de las Naciones Unidas para la Educación, la Ciencia y la Cultura, 2020). Véase al respecto: https://es.unesco.org/cam paign/nextnormal [consultado el 21 de junio de 2021]. 